\title{
Incidence and hormonal stimulation of cows with ovarian hypotrophy
}

\author{
Daniel BEREAN ${ }^{1}$, Liviu Marian BOGDAN ${ }^{1 *}$, Ileana BOGDAN ${ }^{2}$, Anamaria BLAGA PETREAN ${ }^{1}$, Mihai \\ CENARIU $^{1}$, Sidonia BOGDAN ${ }^{1}$
}

${ }^{1}$ Faculty of Veterinary Medicine, University of Agricultural Sciences and Veterinary Medicine from ClujNapoca, 400372, Calea Mănăştur, no. 3-5, Romania

${ }^{2}$ Faculty of Agriculture, University of Agricultural Sciences and Veterinary Medicine from Cluj-Napoca, 400372, Calea Mănăștur, no. 3-5, Romania

*corresponding author: liviu.bogdan@usamvcluj.ro

Bulletin UASVM Veterinary Medicine 77(2)/2020

Print ISSN 1843-5270; Electronic ISSN 1843-5378

doi:10.15835/buasvmcn-vm:2020.0017

\begin{abstract}
The purpose of this research was to establish the incidence and to compare the efficiency of two products used for the hormonal stimulation of ovarian hypotrophy. Gynaecological investigations were performed in 2 farms. The animals with ovarian hypotrophy (ovaries smaller than normal and with a slippery surface) were divided in 2 equal groups depending on the protocol applied: Progesterone (Prid Delta, CEVA) and Progesterone (Dehydroxyprogesterone 10\%, Faculty of Veterinary Medicine Cluj-Napoca). In case of group 1 the treatment was performed with Prid Delta (CEVA), vaginal use, $1.55 \mathrm{~g}$ of progesterone/animal for 7 days. For the animals of group 2 the treatment was performed with Dehydroxyprogesterone, subcutaneous injection, $1.5 \mathrm{~g}$ of dehydroxyprogesterone/ animal for 7 days. For each group were observed: the estrous signals, the interval of estrous apparition, the number of gestation obtained after the first artificial insemination.
\end{abstract}

Keywords: estrous, ovarian hypotrophy, anestrous syndrome.

\section{Introduction}

Fertility of the postpartum period is negatively influenced by the incidence of anestrous. The latter condition is characterized by the absence of estrous behavior, which may be an indication of suboptimal conditions (e.g., inadequate peripartum nutrition) or pathologic conditions (e.g., chronic debilitating diseases or uterine and ovarian diseases) (Peter et al., 2009). Ovarian hypotrophy is one of the most important components of the anestrous syndrome. Anestrous was widely classified into physiologic and pathologic (clinical) types, with the following representing the pathologic type: 1) inactive ovaries; 2 ) silent ovulation; 3 ) ovarian hypofunction; 4) cystic ovarian disease; 5) persistent CL (Mwaanga et al., 2000). The ovarian hypotrophy is more pronounced during the spring $(19.4 \%)$ and winter $(11.8 \%)$ part of the year when cows are solely dependent on winter feeding (Zalesky, 1984). A cow is considered to have a follicular anovulation or ovarian hypofunction when a follicular structure of at least 8-15 mm is detected in two consecutive examinations, in the absence of a corpus luteum or cyst and no estrous signals were noted during the 7 day period between the examinations (López-Gatius et al., 2001). From 1991 to 2000, the cows with ovarian hypofunction received several GnRH-based treatments including the Ovsynch protocol in the late 1990s. The estrous response was very low (usually less than 30\%) using these treatments (Yániz et al., 2004). Since 2001, cows with ovarian 
hypofunction disease had a hormone teraphy with a progesterone-releasing intravaginal device for 9 days. On the 8th day of protocol cows were given a prostaglandin analogue. The estrous response was always higher than $60 \%$ and the pregnancy rate similar to that of cows inseminated at natural estrous (Yániz et al., 2004).

\section{Matherials and Methods}

The study was carried out between April 2018 to September 2018 in a dairy farm from Mures county, Romania, and in a beef farm from Cluj county, Romania, on 192 cows from breeds: Romanian Spotted bread and Aberdeen Angus. A gynaecological evaluation was performed in April 2018 by trans-rectal (TR) exam and TR ultrasonography with the Easy Scan Linear ultrasound. The animals with ovarian hypotrophy (ovaries smaller than normal and with a slippery surface) were randomly divided in 2 groups (Table 1). In case of group 1 the hormonal stimulation was performed with Progesterone (Prid Delta, CEVA), vaginal use, $1.55 \mathrm{~g}$ of progesterone / animal for 7 days. For the animals of group 2 the hormonal stimulation was made with Dehydroxyprogesterone, subcutaneous injection, $1.50 \mathrm{~g}$ of Dehydroxyprogesterone /animal for 7 days. Dehydroxyprogesterone $10 \%$ is a product made at the faculty of the Veterinary Medicine from Cluj Napoca. For each group were observed: the estrous signals, the interval of estrous apparition, the number of gestation obtained after the first artificial insemination.

\section{Results and Discussion}

From 192 investigations in 48 cases was set the ovarian hypotrophy diagnosis. In farm 1, 21 cases of ovarian hypotrophy have been diagnosed and, in second farm, 27 cases of ovarian hypotrophy were diagnosed. In case of group 1 at $91.66 \%$ of animals the estrous signals were observed and in $83 \%$ of cases the animals were pregnant after the first estrous cycle. The interval of estrous apparition had an average of $54 \mathrm{~h}$ after the device removed with values between $44 \mathrm{~h}$ to 93h. In case of group 2 in $87.5 \%$ cases the estrous signals were observed and in $79.16 \%$ the animals were diagnosed pregnant after the first artificial insemination. The estrous interval showed an average of $72 \mathrm{~h}$ after the $7^{\text {th }}$ day of the product administration with limits between $52 \mathrm{~h}$ to $112 \mathrm{~h}$ (Table 2).

Mozaffari et al. reported in 2014 that the rate of observed estrous in a group treated with progesterone was $68 \%$. In our study the rate of estrous detection was $91.66 \%$ for group 1 and $87.5 \%$ for group 2. Conception rate at the first eligible (resynchronized) estrous was just $63 \%$ in a group of cows treated with CIDR (ElZarkouny, 2004). In our research the pregnant rates at the first estrous cycle were $79.16 \%$ for Dexydroxyprogesterone group and $83 \%$ for the Prid delta group.

Table 1. Distribution of animals with ovarian hypotrophy

\begin{tabular}{lccc}
\hline & Prid delta & Dehydroxyprogesterone & Total \\
\hline Farm 1 & 11 & 10 & 21 \\
\hline Farm 2 & 13 & 14 & 27 \\
\hline Total & 24 & 24 & 48 \\
\hline
\end{tabular}

Table 2. The results for each group

\begin{tabular}{ccc}
\hline & Prid delta & Dehydroxyprogesterone \\
\hline Estrous signs & $91.66 \%$ & $87.5 \%$ \\
\hline Pregnants after the first estral cycle & $83 \%$ & $79.16 \%$ \\
\hline Interval of estrous apparition & $54 \mathrm{~h}$ & $72 \mathrm{~h}$ \\
\hline
\end{tabular}




\section{Conclusions}

The administration of Progesterone (Prid Delta or Dexidroxiprogesterone), resulted in apparition of a new estrous cycle in the cows with ovarian hypotrophy. The product performed at the Laborator of the Faculty of Veterinary Medicine (Dehidroxiprogesterone) used in the hormonal stimulation of ovarian hypotrophy leads to a new estrous in $87.5 \%$ of cases, with a pregnancy rate of $79.16 \%$.

Acknowledgments. This research did not receive any specific grant from funding agencies in the public, commercial, or not-for-profit sectors.

\section{References}

1. El-Zarkouny SZ, Stevenson JS (2004). Resynchronizing Estrous with Progesterone or Progesterone Plus Estrogen in Cows of Unknown Pregnancy Status. Journal of Dairy Science, 87(10):3306-3321.
2. López-Gatius F, Santolaria P, Yániz J,Rutllant J, López-Béjar M (2001). Persistent ovarian follicles in dairy cows: a therapeutic approach. Theriogenology 56:649-659.

3. Mozaffari N, Hamali H, Jafari R (2014). Effects of two different protocols: injection of progesterone vs. injection of GnRH-PGF2a on the onset of estrous in dairy cows with postpartum anestrous. International journal of Advanced Biological and Biomedical Research, 2(1):146-150.

4. Mwaanga ES, Janowski T (2000). Anoestrous in dairy cows: causes, prevalence and clinical forms. Reprod Domest Anim, 35:93-200.

5. Peter AT, Vos PL, Ambrose DJ (2009). Postpartum anestrous in dairy cattle. Theriogenology, 71(9):13331342.

6. Yániz JL, Murugavel K, López Gatius F (2004). Recent developments in oestrous synchronization of postpartum dairy cows with and without ovarian disorders. Reprod Domest Anim, 39:86-93.

7. Zalesky DD, Day ML, Garcia-Winder M, Imakawa K, Kittok RJ, D'occhio MJ, Kinder JE (1984). Influence of exposure to bulls on the resumption of estrous cycles following parturition in beef cows. J Anim Sci, 59:1135 1139. 